\title{
Role of Peroral Endoscopic Myotomy in Advanced Achalasia Cardia With Sigmoid and/or Megaesophagus: A Systematic Review and Metanalysis
}

\author{
Harshal S Mandavdhare, ${ }^{1 *}$ Praveen Kumar $\mathrm{M}^{2}$ Jayendra Shukla, ${ }^{1}$ Antriksh Kumar, ${ }^{1}$ and Vishal Sharma ${ }^{1}$ \\ Departments of ${ }^{1}$ Gastroenterology and ${ }^{2}$ Pharmacology, Post Graduate Institute of Medical Education and Research, Chandigarh, India
}

\begin{abstract}
Background/Aims
Sigmoid esophagus and/or megaesophagus are considered as an advanced stage in the natural history of achalasia cardia. The role of peroral endoscopic myotomy (POEM) in these subset of patients is emerging. We performed a systematic review and metanalysis to study the efficacy of POEM in advanced achalasia cardia with sigmoid and megaesophagus.
\end{abstract}

\section{Methods}

A literature search in PubMed and Embase was done from inception till August 3, 2021 to look for studies reporting exclusively on the role of POEM in advanced achalasia cardia with sigmoid and/or megaesophagus. The random effect method with inverse variance approach was used for the computation of pooled prevalence. For 2 groups' analysis of continuous outcome standardized mean difference was used as the summary measure.

\section{Results}

Eleven studies with 428 patients were included for analysis. The pooled technical and clinical success was $98.27 \%(95 \% \mathrm{Cl}, 96.19$ $\left.99.22 ; I^{2}=0 \%\right)$ and $89.38 \%\left(95 \% \mathrm{Cl}, 84.49-92.86 ; I^{2}=26 \%\right)$ and on subgroup analysis into sigmoid and megaesophagus it was $\left(98.06 \%\left[95 \% \mathrm{Cl}, 95.41-99.19 ;\left.\right|^{2}=0 \%\right], 98.47 \%\left[95 \% \mathrm{Cl}, 92.72-99.69 ; \mathrm{I}^{2}=0 \%\right]\right.$ and $87.92 \%\left[95 \% \mathrm{Cl}, 80.68-92.70 ;\left.\right|^{2}=37 \%\right]$, $\left.88.36 \%\left[95 \% \mathrm{Cl}, 62.62-97.17 ; \mathrm{I}^{2}=77 \%\right]\right)$ respectively. The clinical success at $<1$ year and $1-3$ year follow-up was $89.37 \%(95 \% \mathrm{Cl}$, $\left.82.82-93.61 ; I^{2}=0 \%\right)$ and $88.66 \%\left(95 \% \mathrm{Cl}, 81.65-91.22 ; \mathrm{I}^{2}=46 \%\right)$ respectively. There was a significant reduction in the post-POEM scores with standardized mean difference for Eckardt score (4.81), for integrated relaxation pressure at 4 seconds (1.93), and for lower esophageal sphincter pressure (2.06).

\section{Conclusions}

POEM is an effective modality of treatment even in the subset of patients of advanced achalasia cardia with sigmoid and megaesophagus.

(J Neurogastroenterol Motil 2022;28:15-27)

Key Words

Esophageal achalasia; Follow-up studies; Myotomy

Received: June 10, 2021 Revised: September 1, 2021 Accepted: October 4, 2021

() This is an Open Access article distributed under the terms of the Creative Commons Attribution Non-Commercial License (http://creativecommons. org/licenses/by-nc/4.0) which permits unrestricted non-commercial use, distribution, and reproduction in any medium, provided the original work is properly cited.

*Correspondence: Harshal S Mandavdhare, MD, DM Department of Gastroenterology, Postgraduate Institute of Medical Education and Research, F block, Nehru Hospital, PGIMER, Chandigarh 160012, India Tel: +91-9592814877, Fax: +91-9592814877, E-mail: hmandavdhare760@gmail.com 


\section{Introduction}

With over a decade of experience and robust data showing excellent safety and efficacy, peroral endoscopic myotomy (POEM) is now considered as the first line treatment for achalasia cardia. Around $10 \%$ of patients with prolonged duration of disease develop advanced achalasia cardia where there can be either excessive dilatation of the esophagus (megaesophagus with diameter $>6 \mathrm{~cm}$ ) or the axis of the esophagus becomes tortuous taking shape of sigmoid (like sigmoid colon) or both. ${ }^{2,3}$ Traditionally, esophagectomy has been considered the treatment option for this patient cohort, however, it is fraught with high morbidity and mortality. ${ }^{4}$ Due to the extreme tortuosity one would expect difficulty in performing POEM in this subset of patients. Over the years as more and more experience has been gained with POEM for achalasia, we now have some data showing good efficacy even in this subset of advanced achalasia with sigmoid shape and megaesophagus. ${ }^{5}$ Hence, this systematic review and metanalysis was planned to study the efficacy and safety of POEM in the treatment of advanced achalasia cardia with sigmoid and/or megaesophagus.

\section{Methodology for Systematic Review and Meta-analysis}

The Preferred Reporting Items for Systematic Reviews and Meta-analysis (PRISMA) and Meta-analysis of Observational Studies in Epidemiology guidelines were followed for this systematic review and meta-analysis.

We searched the literature for articles that reported exclusively on the role of peroral endoscopic myotomy in advanced achalasia cardia with sigmoid and/or megaesophagus on PUBMED and EMBASE. The search terms used for PUBMED were "advanced achalasia OR Sigmoid achalasia OR Sigmoid esophagus OR Megaesophagus) AND (Peroral myotomy OR Peroral endoscopic myotomy OR POEM)" while for EMBASE were (sigmoid esophagus OR Advanced achalasia OR sigmoid achalasia OR megaesophagus) AND Peroral endoscopic myotomy. The search was done from inception until August 3, 2021.

Two authors (H.S.M. and J.S.) independently searched for articles to be included for the analysis. After comparing the articles screened by both authors, the final list for full text reading was prepared. Any overlap or discrepancy about the data was discussed with and cleared by other co-authors (P.K.M. and V.S.).

We selected those studies published as full text/abstracts in
English language that included $\geq 5$ cases reporting on the role of POEM in the treatment of advanced achalasia cardia with sigmoid and/or megaesophagus. We excluded those studies that included case reports with $<5$ cases, review articles, letter to editor without original data, commentary, articles published in non-English language, and articles that did not exclusively report on the role of POEM in advanced achalasia cardia with sigmoid and/or megaesophagus.

\section{Outcome}

The aim of this systematic review and meta-analysis is to assess the efficacy of POEM for advanced achalasia cardia with sigmoid and/or megaesophagus. The outcomes assessed were: technical success; clinical success; change in Eckardt score (ES), integrated relaxation pressure at 4 seconds $(4 \mathrm{~s}-\mathrm{IRP})$ and lower esophageal sphincter pressure (LESP) pre and post-POEM procedure.

\section{The Outcome Definitions Used in the Study Are as Follows}

(1) The technical success was defined as completion of all the steps of POEM including myotomy and (2) the clinical success was defined as a reduction in the $\mathrm{ES} \leq 3$ post-POEM. The ES is based on 4 symptoms each given score of 0 to 3 with maximum score of $12 .^{6}$ The 4s-IRP and LESP are recorded from the standard software of high-resolution manometry. ${ }^{7}$ In addition we also noted the adverse event rate and was defined as per the American Society of Gastrointestinal Endoscopy (ASGE) lexicon ${ }^{8}$ or International Per Oral Endoscopic Myotomy Survey Classification $(\text { IPOEMS })^{9}$ or Clinical practice guidelines for POEM and Japan Clinical Oncology Group post-operative complications (JCOG PC) criteria $^{10,11}$ or noted as observational data. Apart from this, we looked for the following information: type of study (single/multicentre), type of sigmoid esophagus (Type 1 and Type 2 as per the CT classification-where Type 1 has only single bend and a single lumen on axial cut of CT, while Type 2 is $\mathrm{S}$ shaped and 2 lumens can be seen on axial CT image; ${ }^{12}$ sigmoid and advanced sigmoid as per the descriptive rules of esophageal achalasia-where depending on the $\alpha$ angle [angle between 2 straight lines drawn along the long axis of the esophagus] it is defined a sigmoid when the $\alpha$ angle is $<$ $135^{\circ}$ and $>90^{\circ 13}$ and advanced sigmoid when the $\alpha$ angle is $<90^{\circ}$ and megaesophgus if diameter is $>6 \mathrm{~cm}^{14}$ ), type of achalasia cardia as per the Chicago classification version 3.0, duration of symptoms in months, average diameter of the esophagus, previous treatments 


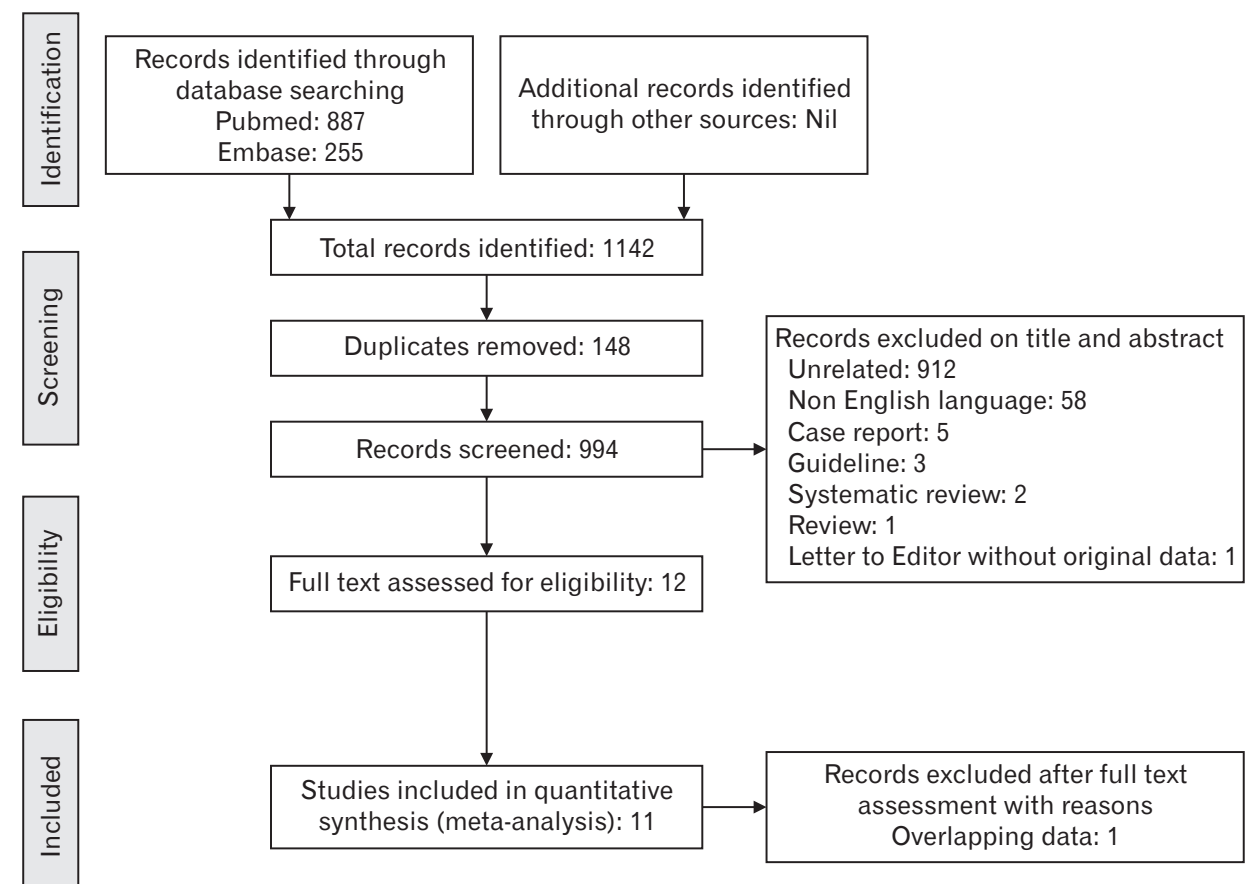

Figure 1. Preferred Reporting Items for Systematic Reviews and Meta-analyses (PRISMA) figure showing the flow of studies included in the meta-analysis. received, pre- and post-ES, pre- and post-4s-IRP, pre- and postLESP, duration of follow-up, myotomy length, and definition used for sigmoid esophagus by individual study. For missing data in abstracts, we contacted the authors through electronic mail.

We also performed separate subgroup analysis of studies that reported on sigmoid esophagus and those that reported on megaesophagus. Apart from this, based on the follow-up period available we performed subgroup analysis of clinical success into 2 groups, viz, clinical success with follow-up $<1$ year and that with follow-up between 1-3 years.

\section{Risk of Bias and Quality Assessment of Studies}

We used the Joanna Briggs Index for critical appraisal of case series and cohort studies to assess the quality of studies ( 2 independent authors H.S.M. and J.S. performed the appraisal). For assessment of publication bias, the funnel plot was used and quantitative analysis was done with Egger's test.

\section{Statistical Analysis}

The statistical analysis was conducted using $\mathrm{R}$ version 4.1.0 and in addition to the base package, the "meta" package was used for the analysis. The random effect method with inverse variance approach was used for the computation of pooled prevalence. The prevalences were logit transformed before computing summary. For 2 groups' analysis of continuous outcomes (pre- and post-), standardized mean difference (SMD) was used as the summary measure and was calculated by the Hedges' $\mathrm{g}$ method and the computation of summary across studies was performed by random effect method with inverse variance approach was used. Both $\mathrm{I}^{2}$ and $P$-value of significance were used for the assessment of heterogeneity or metanalysis. For $\mathrm{I}^{2}$, a value of $>50 \%$ and for $P$-value of significance a value $<0.1$ were kept for assessing heterogeneity for different variables. Sensitivity analysis was performed for data showing marked heterogeneity.

\section{Results}

After screening total 1142 studies we finally included 11 studies (9 full text and 2 abstracts) with 428 patients for meta-analysis. Figure 1 shows the Preferred Reporting Items for Systematic Reviews and Meta-analyses (PRISMA) flowchart for the included studies. Table 1 shows the detailed demographic data of the included studies. ${ }^{3,14-22}$ The study that fulfilled the inclusion criteria but was excluded with reason for exclusion is found in (Supplementary Table). ${ }^{16,23}$ Of these 11 studies, 9 were single center retrospective and 1 each was single center prospective and multicenter retrospective. 


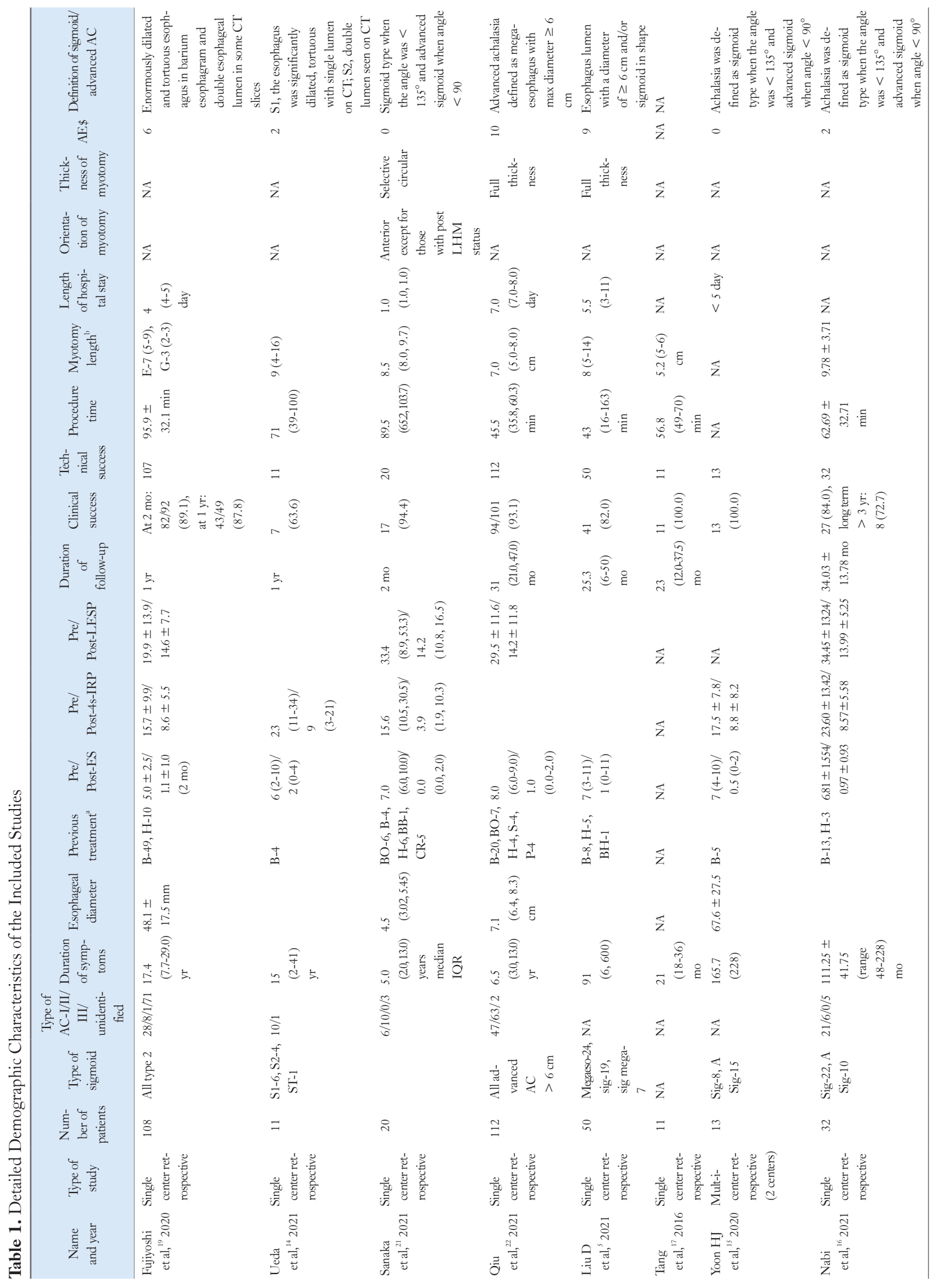




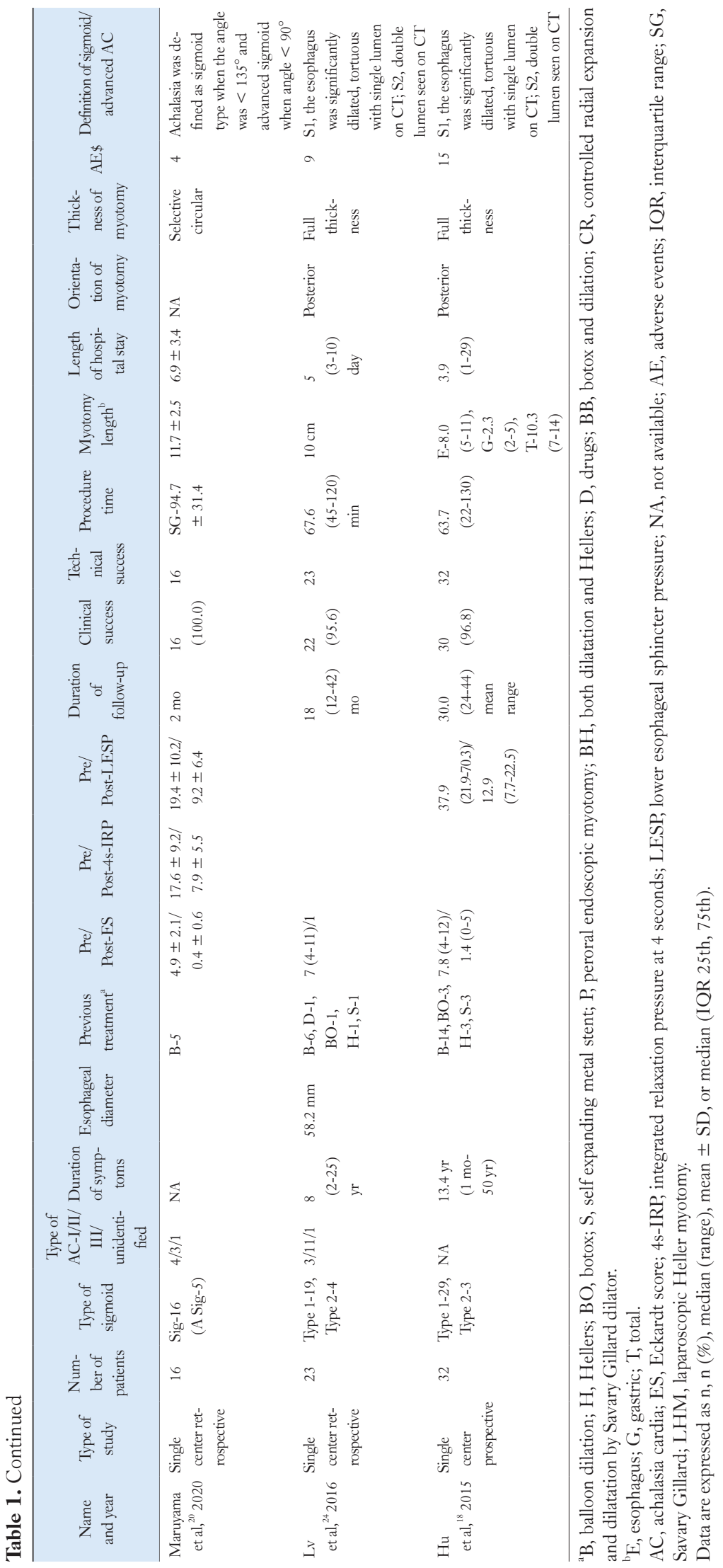


Technical success - Overall

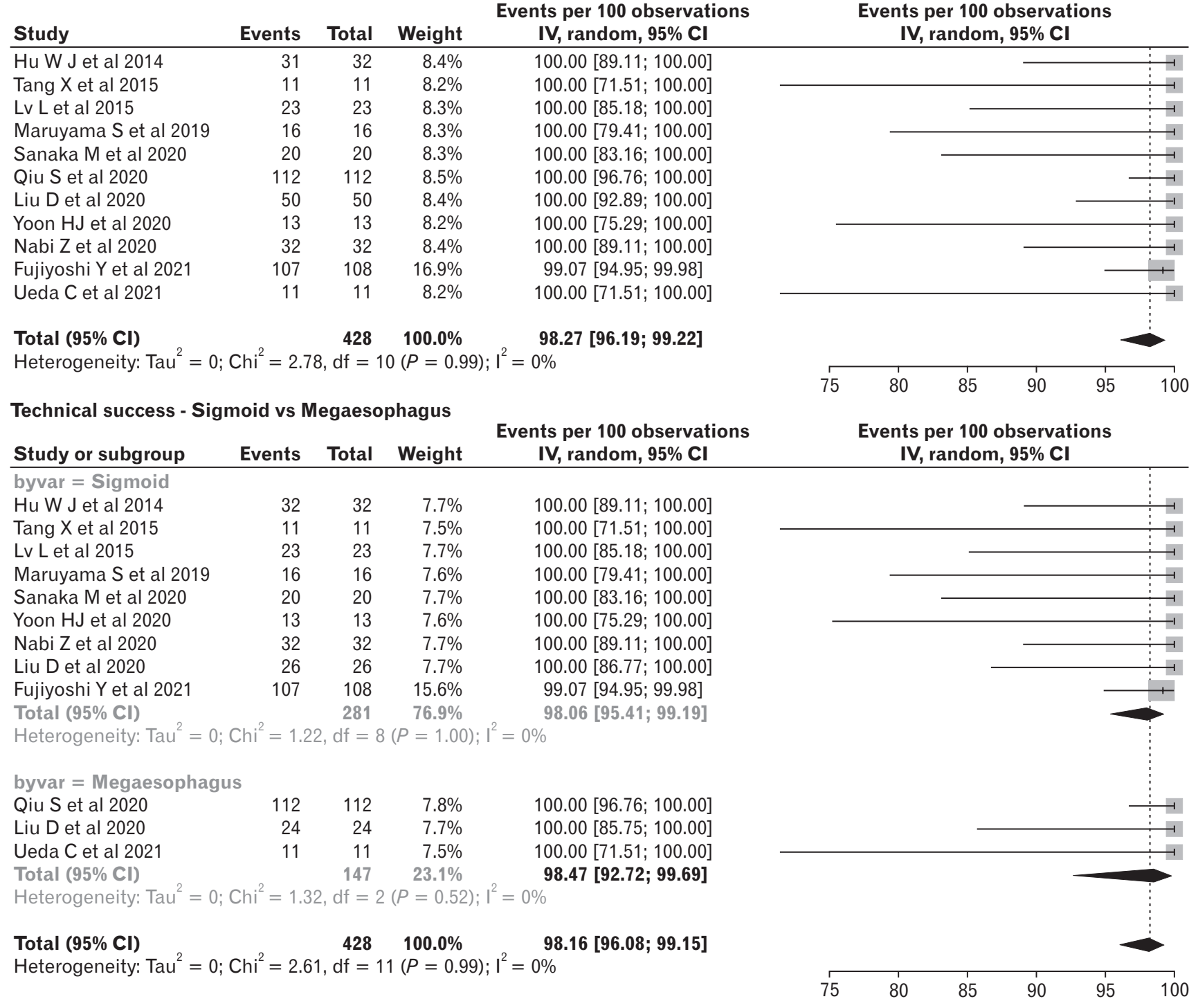

Figure 2. Technical success. The pooled prevalence of technical success for peroral endoscopic myotomy in advanced achalasia cardia (overall) with subgroup analysis and pooled prevalence for sigmoid and megaesophagus.

All the 11 studied reported on technical and clinical success of POEM for advanced achalasia cardia with sigmoid and/or megaesophagus. Eight studies reported on sigmoid esophagus, 2 studies on megaesophagus (Ueda et $\mathrm{al}^{14}$ and Qiu et $\mathrm{al}^{22}$ while 1 study by Liu et al ${ }^{5}$ reported on both sigmoid and megaesophagus. The pooled prevalence for technical success and clinical success was 98.27\% (95\% CI, 96.19-99.22; $\mathrm{I}^{2}=0 \%$ ) and $89.38 \%$ (95\% CI, 84.49-92.86; $\mathrm{I}^{2}=26 \%$ ) respectively (Fig. 2 and 3). On subgroup analysis the pooled prevalence for technical success and clinical success for sigmoid and megaesophagus was $98.06 \%$ (95\% CI, 95.41-99.19; $\left.\mathrm{I}^{2}=0 \%\right), 98.47 \%\left(95 \% \mathrm{CI}, 92.72-99.69 ; \mathrm{I}^{2}=0 \%\right)$ and $87.92 \%$ (95\% CI, 80.68-92.70; $\mathrm{I}^{2}=37 \%$ ), $88.36 \%$ (95\% CI, 62.62-97.17; $\mathrm{I}^{2}=77 \%$ ), respectively (Fig. 2 and 3). On further subgroup analysis, the pooled prevalence for clinical success for studies with follow-up < 1 year (4 studies) was $89.37 \%$ (95\% CI, 82.82-93.61; $\left.\mathrm{I}^{2}=0 \%\right)$ and for those with follow-up between 1-3 years ( 7 studies) was $88.66 \%\left(95 \% \mathrm{CI}, 81.65-91.22 ; \mathrm{I}^{2}=46 \%\right)$ respectively (Fig. 2 and 3). Only 1 study by Nabi et a ${ }^{16}$ had a followup of $>3$ years with a clinical success of $72.7 \%$ (8/11). Three studies mentioned modified technique of POEM for advanced achalasia cardia, viz, (1) $\mathrm{Lv}$ et $\mathrm{al}^{24}$ - described creation of a wider tunnel reaching up to half the esophageal circumference and start- 
Clinical success - Overall

\begin{tabular}{|c|c|c|c|c|}
\hline Study & Events & Total & Weight & $\begin{array}{l}\text { Events per } 100 \text { observati } \\
\text { IV, random, } 95 \% \mathrm{CI}\end{array}$ \\
\hline Hu W J et al 2014 & 30 & 31 & $4.2 \%$ & 96.77 [83.30; 99.92] \\
\hline Tang X et al 2015 & 11 & 11 & $2.2 \%$ & $100.00[71.51 ; 100.00]$ \\
\hline Lv L et al 2015 & 22 & 23 & $4.2 \%$ & 95.65 [78.05; 99.89] \\
\hline Maruyama S et al 2019 & 16 & 16 & $2.3 \%$ & $100.00[79.41 ; 100.00]$ \\
\hline Sanaka M et al 2020 & 17 & 20 & $9.5 \%$ & $85.00[62.11 ; 96.79]$ \\
\hline Qiu S et al 2020 & 94 & 101 & $17.6 \%$ & $93.07[86.24 ; 97.17]$ \\
\hline Liu D et al 2020 & 41 & 46 & $14.0 \%$ & $89.13[76.43 ; 96.38]$ \\
\hline Yoon HJ et al 2020 & 13 & 13 & $2.2 \%$ & $100.00[75.29 ; 100.00]$ \\
\hline Nabi Z et al 2020 & 27 & 32 & $13.6 \%$ & $84.38[67.21 ; 94.72]$ \\
\hline Fujiyoshi Y et al 2021 & 82 & 92 & $20.7 \%$ & 89.13 [80.92; 94.66] \\
\hline Ueda C et al 2021 & 7 & 11 & $9.5 \%$ & $63.64[30.79 ; 89.07]$ \\
\hline Total $(95 \% \mathrm{CI})$ & & 396 & $100.0 \%$ & $89.38[84.49 ; 92.86]$ \\
\hline
\end{tabular}

Clinical success - Sigmoid vs Megaesophagus

Total $(95 \% \mathrm{CI})$ $396 \quad 100.0 \%$

Heterogeneity: Tau $^{2}=0.1702 ; \mathrm{Chi}^{2}=15.63, \mathrm{df}=11(P=0.16) ; \mathrm{I}^{2}=30 \%$

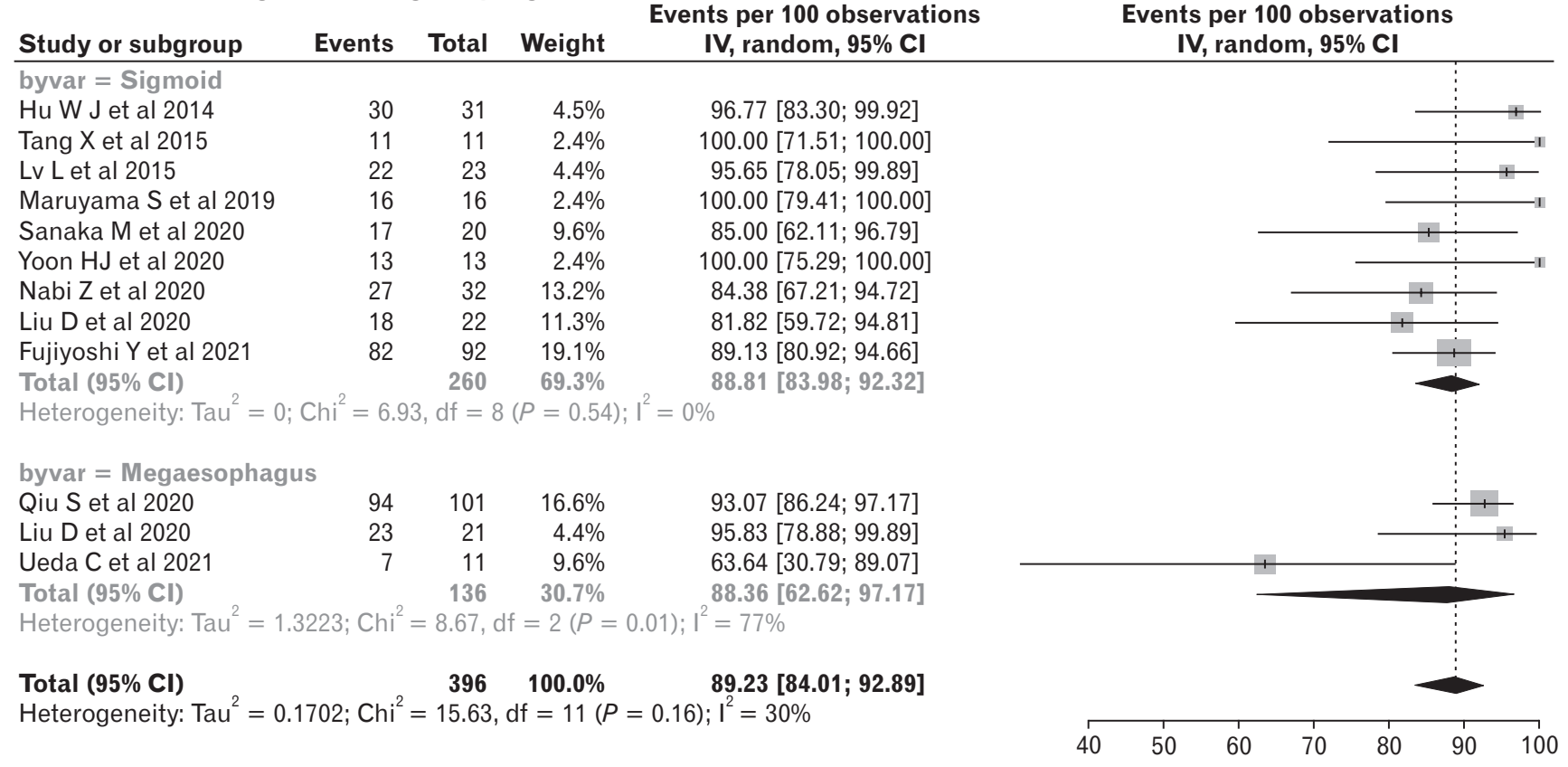

Events per 100 observations IV, random, $95 \% \mathrm{CI}$

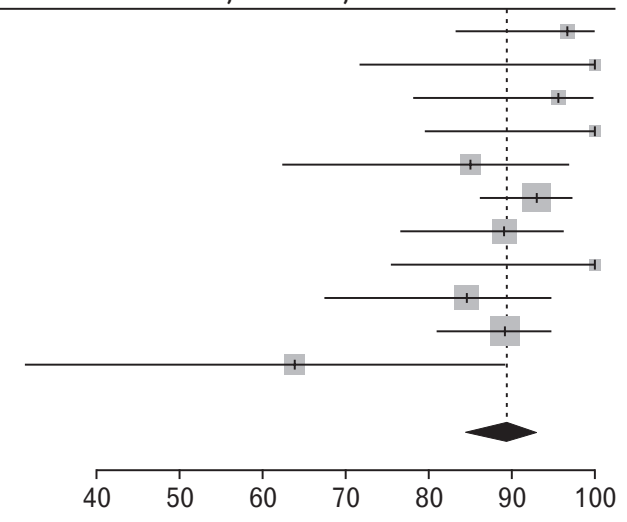

Events per 100 observations IV, random, $95 \% \mathrm{CI}$

Figure 3. Clinical success. The pooled prevalence of clinical success for peroral endoscopic myotomy in advanced achalasia cardia (overall) with subgroup analysis and prevalence for sigmoid and megaesophagus and further subgroup analysis for follow-up $<1$ year and between 1-3 years.

ing myotomy $0-1 \mathrm{~cm}$ from the incision to shorten the tunnel; (2) Qiu et $\mathrm{al}^{22}$ described a reverse $\mathrm{T}$ incision for entry, a "short tunnel POEM" ${ }^{25}$ with a tunnel of 6-8 cm and a myotomy of 3-6 cm and simultaneous submucosal and muscle dissection in case of submucosal fibrosis; ${ }^{26}$ (3) Liu et $\mathrm{al}^{27}$ described modified POEM with tunnelling and myotomy into a single step.

For assessing the efficacy of the procedure, 10 studies (excluding the study by Tang et $\mathrm{al}^{17}$ ) had pre- and post- values of ES for comparison. Seven studies had pre- and post-values of 4s-IRP and LESP for comparison. The SMD for ES, 4s-IRP, and LESP, when compared pre- and post-POEM were 4.81 ([95\% CI, 3.09- $\left.6.62 ; \mathrm{I}^{2}=97 \%\right]$ and for megaesophagus $5.8[95 \% \mathrm{CI},-0.65-$ $\left.12.24 ; \mathrm{I}^{2}=99 \%\right]$ ), for 4s-IRP of 1.93 (95\% CI, 1.09-2.76; $\mathrm{I}^{2}=$ $83 \%)$ and for lower esophageal sphincter pressure of $2.06(95 \%$ CI, 1.13-2.99; $\mathrm{I}^{2}=88 \%$ ), and all were significant (Fig. 4). For the clinical success parameter which is our main outcome parameter, there is no heterogeneity seen as assessed by $\mathrm{I}^{2}$ value of $<50 \%$. But for the continuous outcome (ES, IRP, and LESP) compared pre- and post-, heterogeneity $\left(\mathrm{I}^{2}\right.$ value of $\left.>50 \%\right)$ is seen. We conducted sensitivity analyses on these analyses, to detect the source of heterogeneity. For the ES, the Qiu et $\mathrm{al}^{22} 2021$ study was the study with the maximum contribution to heterogeneity, and excluding the 
Clinical success - Follow up: 1 year vs 1-3 years

\begin{tabular}{|c|c|c|c|c|}
\hline Study or subgroup & Events & Total & Weight & $\begin{array}{c}\text { Events per } 100 \text { observati } \\
\text { IV, random, } 95 \% \mathrm{CI}\end{array}$ \\
\hline \multicolumn{5}{|l|}{ byvar $=\mathrm{FU}<1 \mathrm{yr}$} \\
\hline Maruyama S et al 2019 & 16 & 16 & $1.8 \%$ & $100.00[79.41 ; 100.00]$ \\
\hline Sanaka M et al 2020 & 17 & 20 & $8.1 \%$ & $85.00[62.11 ; 96.79]$ \\
\hline Yoon HJ et al 2020 & 13 & 13 & $1.8 \%$ & $100.00[75.29 ; 100.00]$ \\
\hline Fujiyoshi Y et al 2021 & 82 & 92 & $19.1 \%$ & $89.13[80.92 ; 94.66]$ \\
\hline Total $(95 \% \mathrm{CI})$ & & 141 & $30.9 \%$ & $89.37[82.82 ; 93.61]$ \\
\hline \multicolumn{5}{|c|}{ Heterogeneity: $\mathrm{Tau}^{2}=0 ; \mathrm{Chi}^{2}=1.97, \mathrm{df}=3(P=0.58) ; I^{2}=0 \%$} \\
\hline \multicolumn{5}{|l|}{ byvar = FU 1-3 yr } \\
\hline Hu W J et al 2014 & 30 & 31 & $3.5 \%$ & 96.77 [83.30; 99.92] \\
\hline Lv L et al 2015 & 22 & 23 & $3.5 \%$ & 95.65 [78.05; 99.89] \\
\hline Qiu S et al 2020 & 94 & 101 & $15.9 \%$ & $93.07[86.24 ; 97.17]$ \\
\hline Liu D et al 2020 & 41 & 46 & $12.4 \%$ & 89.13 [76.43; 96.38] \\
\hline Nabi Z et al 2020 & 27 & 32 & $11.9 \%$ & $84.38[67.21 ; 94.72]$ \\
\hline Fujiyoshi Y et al 2021 & 43 & 49 & $13.9 \%$ & 87.76 [75.23; 95.37] \\
\hline Ueda C et al 2021 & 7 & 11 & $8.1 \%$ & $63.64[30.79 ; 89.07]$ \\
\hline & & 293 & $69.1 \%$ & $88.66[81.65 ; 93.22]$ \\
\hline \multicolumn{5}{|c|}{ Heterogeneity: $\mathrm{Tau}^{2}=0.2472 ; \mathrm{Chi}^{2}=11.01, \mathrm{df}=6(P=0.09) ; \mathrm{I}^{2}=46 \%$} \\
\hline
\end{tabular}

Total $(95 \% \mathrm{Cl})$

$434 \quad 100.0 \%$

88.95 [84.51; 92.24]

Heterogeneity: $\mathrm{Tau}^{2}=0.0943 ; \mathrm{Chi}^{2}=13.01, \mathrm{df}=10(P=0.22) ; \mathrm{I}^{2}=23 \%$

Events per 100 observations IV, random, $95 \%$ CI

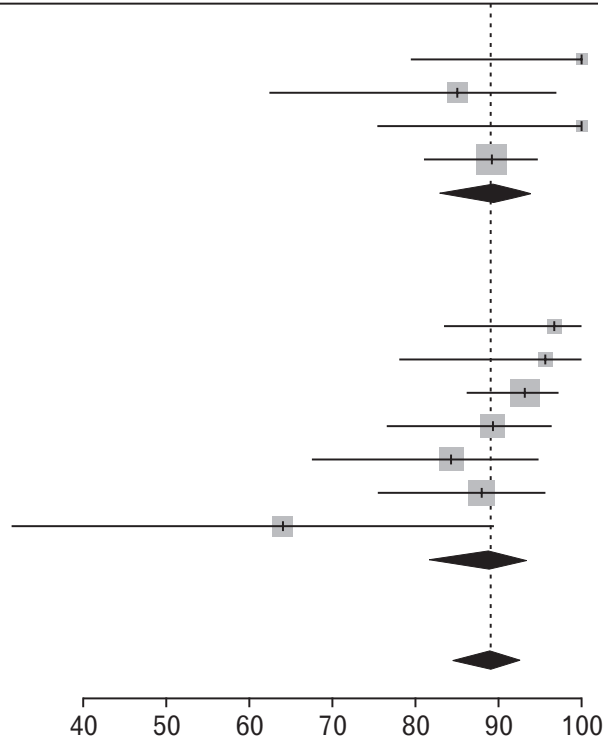

Figure 3. Continued.

study changed the pooled effect size to 3.54 (2.62-4.46) with $\mathrm{I}^{2}=$ 90\%. (Supplementary Fig. 1). For the 4s-IRP, the Lv et al ${ }^{24} 2016$ was the study with maximum contribution to heterogeneity, and excluding the study changed the heterogeneity to $7 \%$ with pooled effect size of 1.22 (0.89-1.54) (Supplementary Fig. 2). For the LESP, Lv et al ${ }^{24} 2016$ was the study with maximum contribution to heterogeneity, and excluding the study changed the heterogeneity to $80 \%$ with pooled effect size of $1.53(0.83-2.24)$ (Supplementary Fig. 3).

Out of the 11 studies, 2 studies mentioned adverse events as per the ASGE lexicon (Qiu et $\mathrm{al}^{22}$ and $\mathrm{Lv}$ et $\mathrm{al}^{24}$ ) while 2 studies used other criteria (Ueda et $\mathrm{al}^{14}$ [IPOEMS] and Maruyama et $\mathrm{al}^{20}$ [Clinical practice guidelines for POEM and JCOG PC] criteria). Five studies mentioned the adverse events as observations without using any criteria (Nabi et al, ${ }^{16} \mathrm{Hu}$ et al, ${ }^{18}$ Fujiyoshi et al, ${ }^{19}$ Sanaka et $\mathrm{al}^{21}{ }^{21}$ and $\mathrm{Lv}$ et $\mathrm{al}^{24}$ ). Two studies (Yoon et $\mathrm{al}^{15}$ and Tang et $\mathrm{al}^{17}$ ) did not mention adverse events in their results. We conducted analysis for adverse events, however, there was marked heterogeneity among the studies, hence, it was decided to exclude adverse event rate from analysis and to only mention the details of adverse events from individual studies in Tables 1 and 2 (Table 1 provides the adverse event rate of individual studies while Table 2 discusses in details the various adverse events that were encountered in each study). The adverse event rate was found between $0.0-46.8 \%$. Of particular mention are the 2 studies by $\mathrm{Hu}$ et $\mathrm{al}^{18}$ and $\mathrm{Lv}$ et $\mathrm{al}^{24}$ which reported very high rates of adverse events (Table 1). However, they included expected inconsequential intraoperative events like subcutaneous emphysema and capnoperitoneum/capnothorax as adverse event which lead to false impression of high adverse event rate.

\section{Quality Assessment (See Table 3)}

Nine of the 11 studies fulfilled all the criteria of the Joanna Briggs critical appraisal tool for case series and cohort studies. $^{5,14-16,18,20-22,24}$ Two of the abstracts that were included were unclear regarding the statistical methods used for analysis ${ }^{17,19}$ while 1 abstract was unclear regarding demographics of the participants and did not report the outcomes and follow-up results clearly. ${ }^{5}$ The funnel plot for publication bias assessed for prevalence for clinical success showed no bias. Also, on quantitative analysis, Egger's test performed on the clinical success data does not indicate the presence of funnel plot asymmetry (intercept 0.835 [95\% CI, -0.69 to $-2.36 ; P=0.311]$ ) (Fig. 5).

\section{Discussion}

The present metanalysis shows that POEM is an effective modality of treatment for both groups of sigmoid and megaesophagus in advanced achalasia cardia with a pooled technical success of $98.27 \%$ and clinical success of $89.38 \%$. The clinical success was 


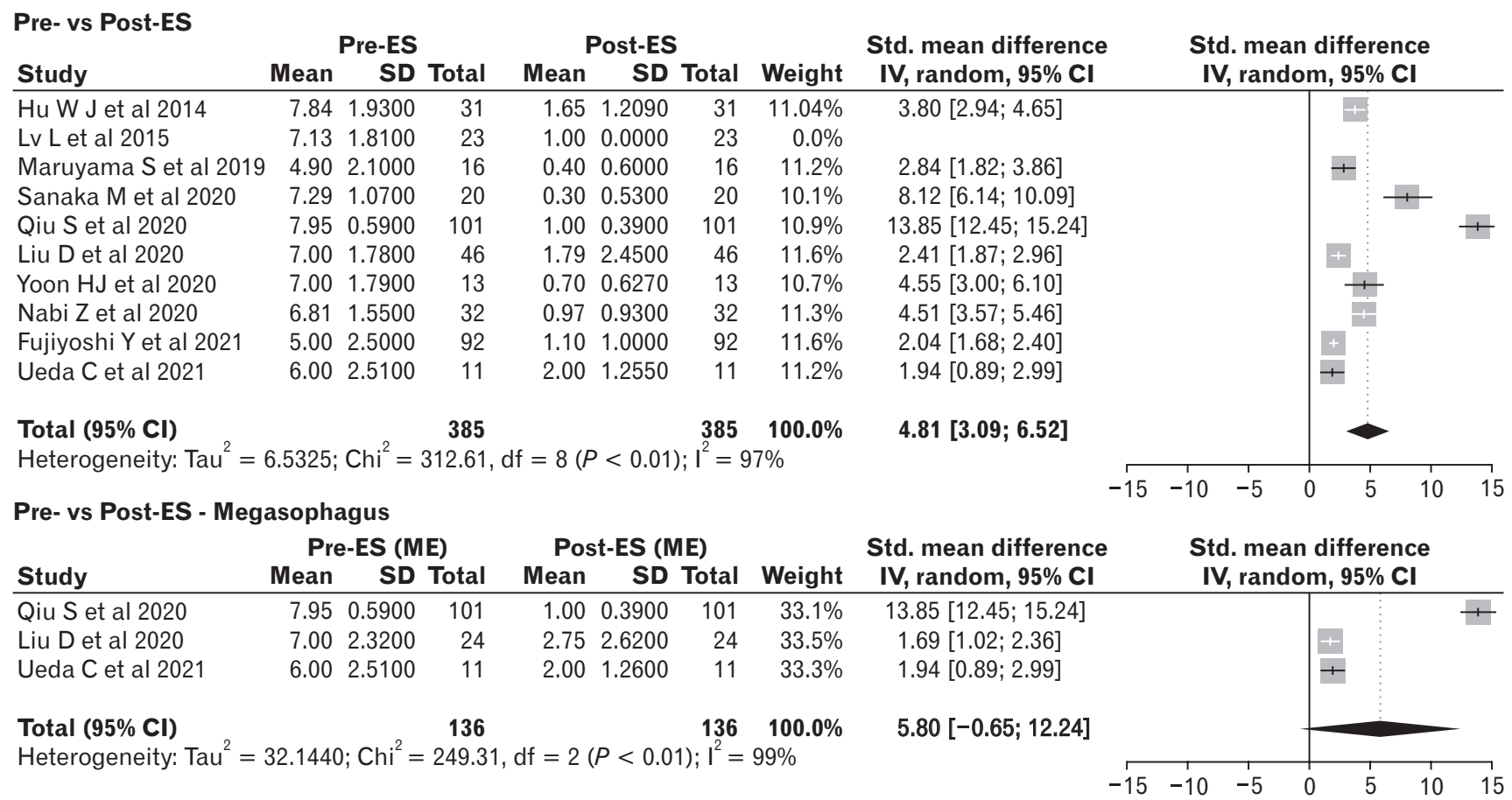

Pre- vs Post-LESP

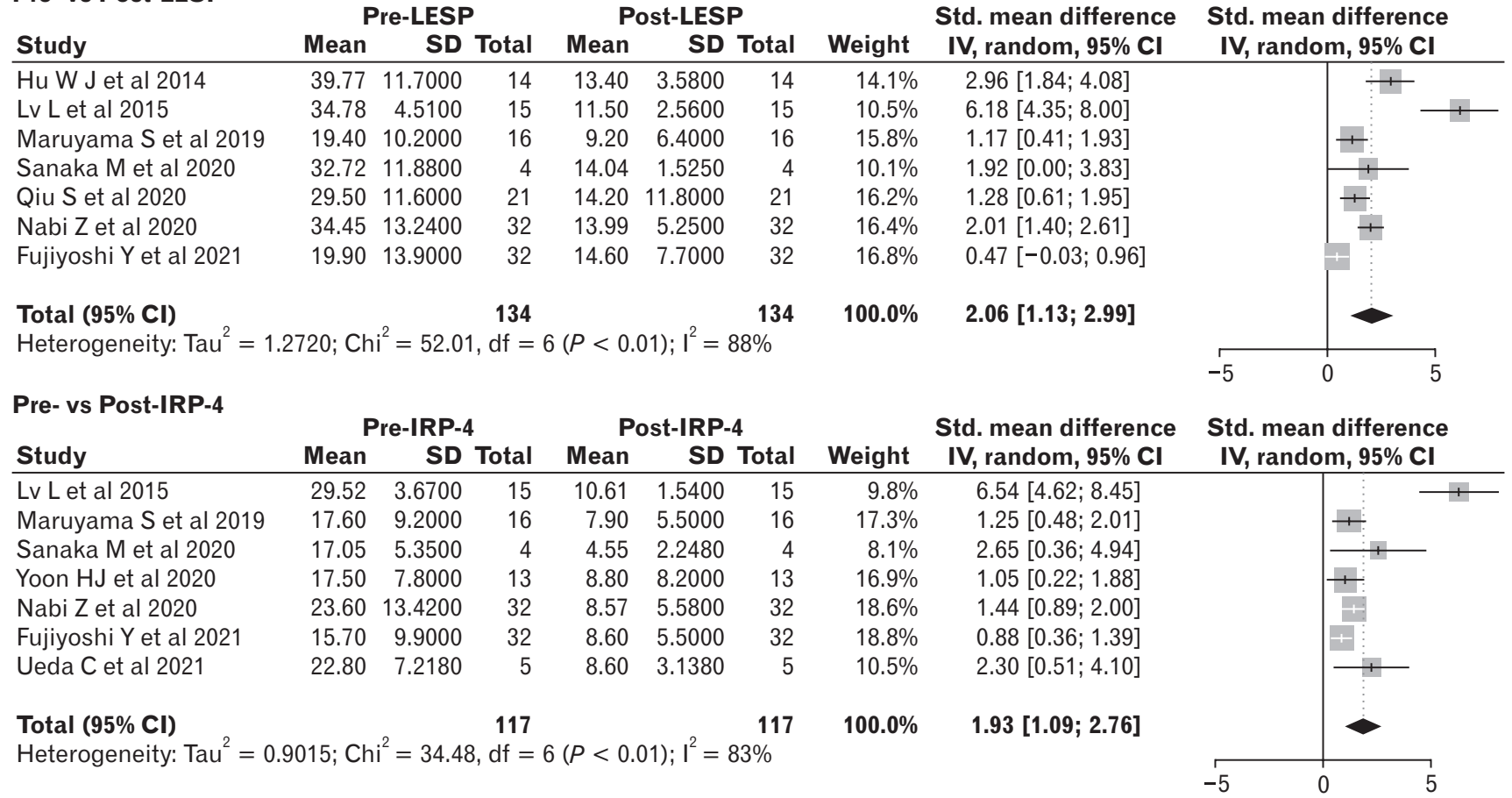

Figure 4. Standardized mean difference of pre and post-peroral endoscopic myotomy-Eckardt score (ES), 4-second integrated relaxation pressure $(4 s-I R P)$ and lower esophageal sphincter pressure (LESP) are shown.

comparable between both the sigmoid $(87.92 \%)$ and the megaesophagus $(88.36 \%)$ groups with sustained rate until 3 years of follow-up $(88.66 \%)$. The post-POEM scores showed a significant reduction with SMD for $\mathrm{ES}$ of 4.81 , for 4 s-IRP of 1.93 , and for
LESP of 2.06 respectively. Thus, not only subjective scores (ES) but also objective scores (4s-IRP and LESP) have shown significant improvement post-POEM in advanced achalasia cardia with sigmoid and/or megaesophagus. 
Table 2. Details of Adverse Events From Each Study Along With Gastroesophageal Reflux Disease Rate ${ }^{a}$

\begin{tabular}{|c|c|c|}
\hline Study and year & Adverse events reported & GERD rate \\
\hline Fujiyoshi et al, ${ }^{19} 2020$ & Mucosal perforation-3, mucosal hematoma/bleeding-3 & $\begin{array}{l}\text { GERD } 2 \text { mo post-POEM- } \\
\text {-symptoms: 10/88 (11.3\%) } \\
\mathrm{RE}^{\mathrm{b}}: \mathrm{N} / \mathrm{A} / \mathrm{B} / \mathrm{C} / \mathrm{D}-37(42.5 \%), 29(33.3 \%), \\
13(14.9 \%), 7(8.0 \%), 1(1.1 \%) \\
\text { PPI usage rate- } 16.1 \%(13 / 81)\end{array}$ \\
\hline Ueda et al, ${ }^{14} 2021$ & $\begin{array}{l}\text { Failed mucosal entry closure-2 } \\
\text { (needing clip and loop and fibrin glue) }(18.2 \%)\end{array}$ & GERD symptoms-1 $(9.0 \%)$ \\
\hline Sanaka et $\mathrm{al}^{21}{ }^{21} 2021$ & None & GERD symptoms-1 (5.5\%) \\
\hline Qiu et $\mathrm{al}^{22} 2021$ & $\begin{array}{l}\text { Mucosal injury-4 (3.6\%), delayed haemorrhage- } 2(1.8 \%) \text {, } \\
\text { gas-related complications-4 }(3.6 \%) \text {, pneumoperitoneum only, } \\
\mathrm{n}=1 \text {, pneumomediastinum only, } \mathrm{n}=3 \text {, overall-10 }(8.9 \%)\end{array}$ & $\begin{array}{l}\text { GERD symptoms-27 }(26.7 \%) \\
\text { RE: LA-B-5 }(83.3 \%), \text { LA-C-1 }(16.6 \%)\end{array}$ \\
\hline Liu et al, 2021 & $\begin{array}{l}\text { Mucosal injury-2 }(4.0 \%) \text {, bleeding }-3(6.0 \%) \text {, subcutaneous em- } \\
\text { physema-3 }(6.0 \%) \text {, perforation-1 }(2.0 \%) \text {, overall-9 }(18.0 \%)\end{array}$ & $\begin{array}{l}\text { GERD symptoms-13/46 (28.2\%) } \\
\text { RE: LA-A-7 (87.5\%), LA-C-1 }(12.5 \%)\end{array}$ \\
\hline Tang et $\mathrm{al},{ }^{17} 2016$ & Not available & GERD symptoms-2/11 (18.1\%) \\
\hline Yoon et $\mathrm{al},{ }^{15} 2020$ & None & Not available \\
\hline Nabi et al, ${ }^{16} 2021$ & $\begin{array}{l}\text { Delayed mucosal barrier failure-1, symptomatic pleural effusion } \\
\text { needing drainage-1 }\end{array}$ & $\begin{array}{l}\text { Abnormal acid exposure on } 24 \text { hour } \mathrm{pH} \text { study-3 } \\
\text { RE: LA-A-7/18 (38.8\%), LA-B- } 11 / 18(6.1 \%)\end{array}$ \\
\hline Maruyama et al, ${ }^{20} 2020$ & $\begin{array}{l}\text { Mucosal injury-1 (25.0\%), incomplete clipping-2 (50.0\%), } \\
\text { pneumoperitoneum-1 (25.0\%) overall-4 }(25.0 \%)\end{array}$ & RE: LA-N/A/B-9 (56.2\%), 5 (31.2\%), 2 (12.5\%) \\
\hline Lv et al, ${ }^{24} 2016$ & $\begin{array}{l}\text { SCE-7 (30.4\%), MSCE-1 (4.3\%), Mucosal injury } 1(4.3 \%) \text {, } \\
\text { Overall-9 (39.1\%) }\end{array}$ & RE: LA-A-3/23 (13.0\%) \\
\hline Hu et al, ${ }^{18} 2015$ & $\begin{array}{l}\text { Mucosal injury-12 }(37.5 \%) \text {, pneumoperitoneum needing needle } \\
\text { aspiration-2 }(5.8 \%) \text {, pneumothorax needing ICTD under water } \\
\text { seal-1 }(3.1 \%)\end{array}$ & $\begin{array}{l}\text { GERD symptoms-7/31 (22.5\%) } \\
\text { RE: LA-A-5 (71.4\%), LA-C- } 1(14.2 \%)\end{array}$ \\
\hline
\end{tabular}

${ }^{a}$ Major adverse events occurred in 3 studies.

Ueda et $\mathrm{al}^{14}$ : failed mucosal entry closure-2 (needing clip and loop and fibrin glue) (18.2\%).

Liu et $\mathrm{al}^{5}: 2$ patients needed Sengstaken- Blakemore tube for hemostasis-2/50 (4.0\%).

Nabi et $\mathrm{al}^{16}$ : delayed mucosal barrier failure-1, symptomatic pleural effusion needing drainage-1 (2/32 [6.3\%]).

${ }^{\mathrm{b}} \mathrm{N} / \mathrm{A} / \mathrm{B} / \mathrm{C} / \mathrm{D}$ - Los Angeles (LA) grading of reflux esophagitis.

GERD, gastroesophageal reflux disease; POEM, peroral endoscopic myotomy; RE, reflux esophagitis; PPI, proton pump inhibitor; SCE, subcutaneous emphysema; MSCE, mediastinal + subcutaneous emphysema; ICTD, intercostal drain.

During the initial years of introduction of POEM, it was believed that the anatomical distortion because of the sigmoid shape in advanced achalasia cardia would render it difficult to perform POEM in this subset of patients, however, as more and more experience was gained, data have now emerged where POEM has shown good efficacy even in this subset of patients.

This metanalysis shows technical and clinical success of POEM for advanced achalasia cardia with sigmoid and/or megaesophagus of $98 \%$ and $89 \%$, respectively, which is similar to the efficacy of POEM seen in routine cases of achalasia cardia. ${ }^{1,28}$ There was marked heterogeneity in the reporting rate of adverse events among the included studies (0-47\%) due to the usage of various definitions and inclusion of inconsequential intraoperative events as adverse events. Hence, we decided not to include adverse events as our outcome measure and to only provide details of the same in tabular form (Tables 1 and 2). In routine cases of achalasia cardia the adverse event rate for mild events is seen in up to $5 \%$, moderate up to $8 \%$ and severe up to $3 \%{ }^{28}$ The majority of the included studies reported adverse event rate $<10 \%$ with 2 studies reporting $0 \%$ rate (Table 1). Also, most studies reported mild events except for 3 studies which reported major events requiring intervention (Liu et al, ${ }^{5}$ Ueda et al, ${ }^{14}$ and Nabi et $\left.\mathrm{al}^{16}\right)$. Thus, from this data POEM appears to be a safe procedure in this technically difficult subset as well.

As advanced achalasia cardia with sigmoid and/or megaesophagus is considered an end stage burnt out disease one would expect the morphological alterations that take place to be permanent and non-modifiable even with treatment. However, POEM has shown promising results even in this parameter with morphological restoration by reducing the diameter of the esophageal body and increas- 


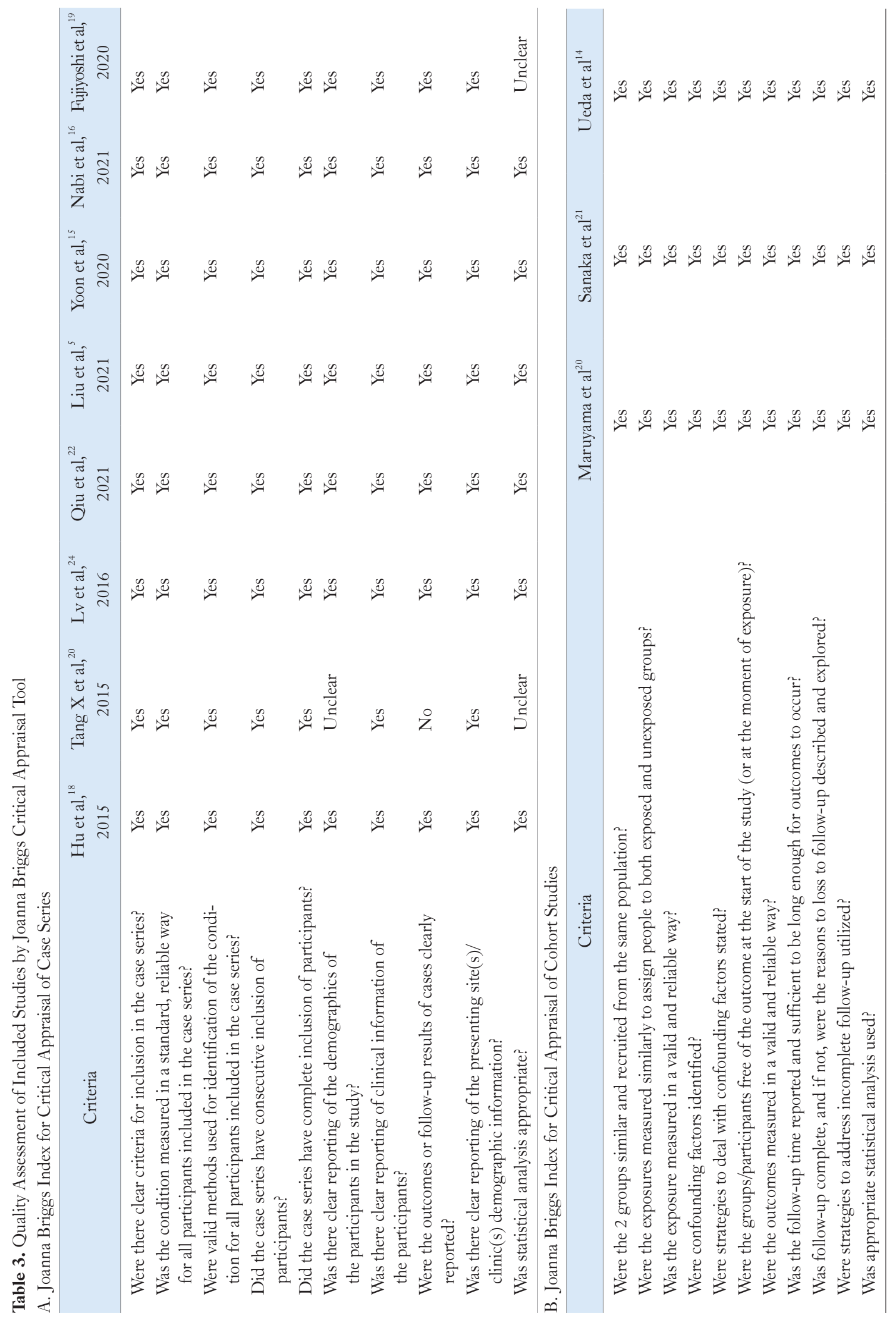




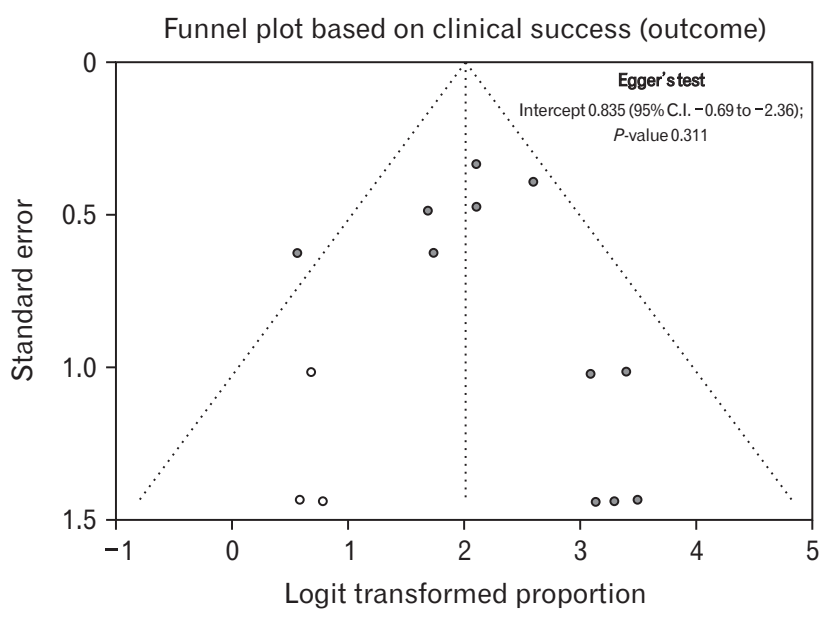

Figure 5. Funnel plot showing no publication bias with quantitative analysis by Egger's test showing no asymmetry in the plot.

ing the diameter of esophagogastric junction opening, and also widening the angulations from acute to more obtuse angles as shown in 3 of the included studies. ${ }^{14,15,20}$ However, the study by Nabi et $\mathrm{al}^{16}$ involving 32 patients has shown that there is deterioration of both symptom score (ES) and free flow of barium at $>1$ year of followup, suggesting the need of close watch in this subset of patients.

The strengths of this metanalysis are good number of studies $(n=11)$ and sample $(n=428)$ given the uncommon presentation of this subset. Also, the main outcomes, viz, clinical and technical success did not show any heterogeneity. We also conducted subgroup analysis for sigmoid and megaesophagus along with the analysis of the clinical success with follow-up $<1$ year and between 1-3 years, thereby reducing the heterogeneity. We also performed sensitivity analysis for data showing marked heterogeneity. The limitations of the metanalysis are retrospective study design of majority of the included studies with the associated confounding factors. The parameters (both subjective and objective) to assess the clinical efficacy post-POEM showed significant heterogeneity. The possible reasons could be variation in the study design, outcome parameter measurement as well as sample size between the different included studies. Apart from these, the other important limitations include variation in definition of sigmoid achalasia in different studies, variability in the reporting of adverse events, and variable follow-up periods as low as 2 months in some studies.

\section{Conclusion}

Based on the results of this metanalysis, POEM appears to be an effective modality of treatment for advanced achalasia cardia with sigmoid and megaesophagus. We need appropriately powered randomized trials and long-term data to confirm the above findings.

\section{Supplementary Materials}

Note: To access the supplementary table and figures mentioned in this article, visit the online version of Journal of Neurogastroenterology and Motility at http://www.jnmjournal.org/, and at https:// doi.org/10.5056/jnm21122.

\section{Financial support: None.}

\section{Conflicts of interest: None.}

Author contributions: Concept and design of the study: Harshal S Mandavdhare; collecting and interpreting the data: Harshal S Mandavdhare, Praveen Kumar M, Jayendra Shukla, Antriksh Kumar, and Vishal Sharma; statistical analysis: Praveen Kumar M; drafting the initial manuscript: Harshal S Mandavdhare and Praveen Kumar M; manuscript revision and important contribution of intellectual content: Harshal S Mandavdhare, Praveen Kumar M, and Vishal Sharma; and final approval: all authors.

\section{References}

1. Mundre P, Black CJ, Mohammed N, ford AC. Efficacy of surgical or endoscopic treatment of idiopathic achalasia: a systematic review and network meta-analysis. Lancet Gastroenterol Hepatol 2021;6:30-38.

2. Shiino Y, Houghton SG, Filipi CJ, Award ZT, Tomonaga T, Marsh RE. Manometric and radiographic verification of esophageal body decompensation for patients with achalasia. J Am Coll Surg 1999;189:158-163.

3. Mattioli S, Di Simone MP, Bassi F, et al. Surgery for esophageal achalasia. long-term results with three different techniques. Hepatogastroenterology 1996;43:492-500.

4. Aiolfi A, Asti E, Bonitta G, Bonavina L. Esophagectomy for endstage achalasia: systematic review and meta-analysis. World J Surg 2018;42:1469-1476.

5. Liu D, Liu YY, Chen JX, et al. Influence of esophageal morphology on the clinical efficacy of peroral endoscopic myotomy in treating advanced achalasia cardia. Exp Ther Med 2021;21:196.

6. Eckardt VF, Aignherr C, Bernhard G. Predictors of outcome in patients with achalasia treated by pneumatic dilation. Gastroenterology 1992;103:1732-1738.

7. Kahrilas PJ, Bredenoord AJ, Fox M, et al. The Chicago classification of esophageal motility disorders, v3.0. Neurogastroenterol Motil 2015;27:160-174.

8. Cotton PB, Eisen GM, Aabakken L, et al. A lexicon for endoscopic adverse events: report of an ASGE w orkshop. Gastrointest Endosc 2010;71:446-454. 
9. Stavropoulos SN, Modayil RJ, Friedel D, Savides T. The international per oral endoscopic myotomy survey (IPOEMS): a snapshot of the global POEM experience. Surg Endosc 2013;27:3322-3338.

10. Inoue $\mathrm{H}$, Shiwaku $\mathrm{H}$, Iwakiri $\mathrm{K}$, et al. Clinical practice guidelines for peroral endoscopic myotomy. Dig Endosc 2018;30:563-579.

11. Katayama H, Kurokawa Y, Nakamura K, et al. Extended Clavien-Dindo classification of surgical complications: Japan clinical oncology group postoperative complications criteria. Surg Today 2016;46:668-685.

12. Inoue H, Minami H, Kobayashi $\mathrm{Y}$, et al. Peroral endoscopic myotomy (POEM) for esophageal achalasia. Endoscopy 2010;42:265-271.

13. Japan Esophageal Society. Descriptive rules for achalasia of the esophagus, june 2012: 4th Edition. Esophagus 2017;14:275-289.

14. Ueda C, Abe H, Tanaka S, et al. Peroral endoscopic myotomy for advanced achalasia with megaesophagus. Esophagus 2021;18:922-931.

15. Yoon HJ, Lee JE, Jung DH, Park JC, Toun YH, Park H. Morphologic restoration after peroral endoscopic myotomy in sigmoid-type achalasia. J Neurogastroenterol Motil 2020;26:67-73.

16. Nabi Z, Ramchandani M, Basha J, Goud R, Darisetty S, Reddy DN. Outcomes of per-oral endoscopic myotomy in sigmoid and advanced sigmoid achalasia. J Gastrointest Surg 2021;25:530532.

17. Tang X, Ren Y, Huang S, Gao Q, Gong W. 24th UEG week 2016: Vienna, Austria, October 2016. United European Gastroenterol J 2016;4(5 suppl):i.

18. Hu JW, Li QL, Zhou PH, et al. Peroral endoscopic myotomy for advanced achalasia with sigmoid-shaped esophagus: long-term outcomes from a prospective, single-center study. Surg Endosc 2015;29:28412850.

19. Fujiyoshi Y, Abad MRA, Nishikawa Y, et al. Sa1262 a large single-center study on the clinical outcomes of per-oral endoscopic myotomy for sig- moid type 2 achalasia. Gastrointest Endosc 2020;91:AB138.

20. Maruyama S, Taniyama Y, Sakurai T, et al. Per-oral endoscopic myotomy (POEM) for a sigmoid type of achalasia: short-term outcomes and changes in the esophageal angle. Surg Endosc 2020;34:41244130.

21. Sanaka MR, Garg R, Chadalavada P, et al. Peroral endoscopic myotomy is safe and highly effective treatment for advanced achalasia with sigmoid esophagus. J Clin Gastroenterol 2021;55:505-511.

22. Qiu S, Chai N, Zhai Y, Wang X, Wang Y, Linghu E. Advanced achalasia: good candidate for peroral endoscopic myotomy. Dis Esophagus 2021;34:doaa97.

23. Indian Society of Gastroenterology. Indian J Gastroenterol 2015;34(suppl 1):1-104

24. Lv L, Liu J, Tan Y, Liu D. Peroral endoscopic full-thickness myotomy for the treatment of sigmoid-type achalasia: outcomes with a minimum follow-up of 12 months. Eur J Gastroenterol Hepatol 2016;28:30-36.

25. Li L, Chai N, Linghu E, et al. Safety and efficacy of using a short tunnel versus a standard tunnel for peroral endoscopic myotomy for Ling type IIc and III achalasia: a retrospective study. Surg Endosc 2019;33:13941402.

26. Li Y, LingHu E, Ding H, et al. Peroral endoscopic myotomy with simultaneous submucosal and muscle dissection for achalasia with severe interlayer adhesions. Gastrointest Endosc 2016;83:651-652.

27. Liu BR, Song JT, Omar Jan M. Video of the month. Modified peroral endoscopic myotomy. Am J Gastroenterol 2015;110:499.

28. Mohan BP, Ofosu A, Chandan S, et al. Anterior versus posterior approach in peroral endoscopic myotomy (POEM): a systematic review and meta-analysis. Endoscopy 2020;52:251-258. 